\title{
Managerial view on design for manufacturing
}

\author{
Matti Mottonen*, Janne Harkonen, Pekka Belt and Harri Haapasalo \\ Department of Industrial Engineering and Management \\ P.O. Box 4610, \\ FI-90014 University of Oulu, Finland \\ E-mail: matti.mottonen@oulu.fi \\ E-mail: janne.harkonen@oulu.fi \\ E-mail: pekka.belt@oulu.fi \\ E-mail: harri.haapasalo@oulu.fi
}

*Corresponding author

Jouni Simila

Department of Information Processing Science

P.O. Box 3000,

FI-90014 University of Oulu, Finland

E-mail: jouni.simila@oulu.fi

\begin{abstract}
Purpose - This study provides a tangible example of organisational solutions in effective design for manufacturing (DfM) in a large information and communications technology (ICT) company.

Design/methodology/approach - In this research an interview study was carried out in a leading ICT company to clarify the practical realisation of DfM, and the current challenges encountered. The interviews covered all the key persons involved in DfM and related processes, in a case company that has successfully applied DfM for over a decade.

Findings - This study shows the importance of a separate management organisation for coordinating the requirements of internal functions. With relation to the case company, this organisation, in contrast to literature, is located in production, not in the product development. Despite the successful application of DfM, the case company still has challenges in exploitation of related data systems.

Research limitations/implications - This study describes one of the top companies in its field. However, the obtained results could vary to some degree, should a wider set of companies be included in the study.

Practical implications - Managers of other companies could learn from this example at three levels: organisational solutions for DfM, its practical realisation, and the challenges encountered.

Originality/value - The existing literature is relatively scarce on organisational implications of DfM implementation. This study identifies a functional organisational location, structure, and practical realisation for effective DfM.
\end{abstract}

Keywords: design for excellence, design for manufacturing, industrial management, product development, ICT, data systems

Paper type Research paper

\section{Introduction}

The information and communications technology (ICT) sector is facing continuous change in its new product development (NPD) as products are getting increasingly complicated and customer segments more fragmented. Companies are working in a multi-site, multi-project, multi-cultural environment and organisational changes, such as acquisitions, are frequent. Recently, there has been a trend to relocate production from North America and Europe to East Asia. These changes, together with pressures for shortening development times and severe price erosion, require multidisciplinary approaches. Successful product development necessitates the integration of engineers, industrial designers and marketing personnel. (e.g. Pahl et al., 2007; Belt et al., 2008; Zeidler et al., 2007; Helo, 2004) 
Due to globalisation, companies have to consider transferring production lines from one country to another in order to cut costs. Rather than considering perfect production systems, managers also have to concentrate on quick and tangible measures to address the challenge of the compatibility of data systems and data-bases. In order to remove overlapping, managers must decide which elements of the data systems are relevant and how these elements can adequately communicate with each other. (e.g. Bengtsson and Berggren, 2008).

The importance of early stages of product development is highlighted by many authors (Bralla, 1996; Lau et al., 2007; Harkonen et al., 2009; Gatenby and Foo, 1990; Yang et al. 2007). The ability to influence the success of NPD is the greatest at the start of the project. The choices made in early NPD, reduce both unnecessary changes towards the end, and the total life-cycle costs, even after the end of the project. Design for eXcellence (DfX) is an organised way to systematically address the early involvement and functional integration. DfX and design for six sigma have been two of the most popular concepts in quality management in recent years (Jiang et al., 2007).

Addressing the needs of internal customers has been identified as a key element for successful product development (e.g. Cooper et al., 2004; Gupta et al., 2007). Manufacturing has been the first internal customer aspect that has been addressed, by applying design for manufacturing (DfM). DfX has then expanded from manufacturing to also cover other areas. Requirements for products typically change during product development, and requirements management has become a significant challenge for high tech companies. This challenge is accumulated by the fact that requirements are interpreted differently in different parts of organisations. DfX is a potential way for addressing internal customers and for harmonising practices. DfX can be used to disseminate information and realise the implementation of these practices, besides collecting internal best practices. DfX is discussed in literature, yet descriptions on how companies realise these activities in practice are scarce.

This paper studies the design for manufacturing practices of a leading ICT company, including practical realisation of DfM and the required organisational solutions. In addition, the current challenges are clarified, including related data system aspects. The above mentioned can be condensed into the following research questions:

RQ1. How does a leading ICT company organise its design for manufacturing?

RQ2. What are currently the main challenges of DfM?

\section{Literature review on design for manufacturing}

Researchers refer to product design improvement efforts as design for eXcellence (DfX) where X stands for an aspect under consideration, such as manufacturing, assembly, testability, reliability, disassembly, cost and so on (e.g. Gehin et al., 2008; Barton et al., 2001; Rungtusanatham and Forza, 2005; Jose and Tollenaere, 2005; Haque and James-Moore, 2004; Kuo et al., 2001; Jablokow and Booth, 2006; Tseng, and Jiao, 1998). These aspects can also be divided into function-oriented and process-oriented attributes (Sheu and Chen, 2007). DfX can be seen as an integrated approach for designing products and processes for cost-effective, high quality operations through product life. DfX aims to reduce time-to-market, lower cost, and increase quality of products (e.g. Prasad, 2000; Prasad, 1997; Gungor, and Gupta, 1999). Maltzman et al. (2005) stress quality and customer satisfaction aspects, while Zuidwijk and Krikke (2008) emphasise the reusability viewpoint.

Individual designers have traditionally focused on the product itself and the value it can provide to the end-user (Bralla, 1996). Typically, they do not consider the product realisation through the entire life-cycle, including manufacturing, disposal and such. Only after the design is complete, these issues are addressed and are left for related departments to solve. This has resulted in cumbersome processes that are time-consuming, inflexible and prone to errors (e.g. Huang et al., 2001).

The first attempts to address the needs of internal customers include manufacturing considerations. The literature refers to designing manufacturability, already as early as in the 1940s through 1960s (e.g. Huang, 1996). Examples of the first approaches to address manufacturability include value analysis, value engineering and produceability engineering (Bralla, 1996; Huang et al., 2001). These methods can be seen to share the same philosophical impetus as modern design for excellence. Boothroyd \& Dewhurst (1983) can be interpreted to be the first ones to utilise design for excellence with their concept of design for assembly (DfA). DfA methodology aims to simplify design by both minimising the number of parts and easing their insertion (e.g. Lai and Gershenson, 2008). This 
concept was later broadened into design for manufacturing to include a broader set of manufacturing aspects (e.g. Chang et al., 2005; Stoll, 1988; Chang et al., 2007).

Since 1990s DfX methodology has expanded and is applied in new areas, such as environmental issues (Graedel, 2008; Kurk, and Eagan, 2008; Bras, 1997; Coulter and Bras, 1997; Ehrenfeld and Lenox, 1997; Tichem, 1997). The ultimate goal of design for environment (DfE) is to reduce the overall environmental damage when producing goods and providing services (e.g. Gungor and Gupta, 1999; Dowie, 1994). In addition, design for testability, design for usability, design for safety, design for serviceability, and design for packaging, have since been introduced, to effectively consider versatile aspects during product development. DfX concept, having expanded to new areas, now covers the entire product life-cycle. It has become imperative to coordinate product and process design of product families within a supply chain framework. (Jiao et al., 2007; Bralla, 1996; Gatenby and Foo, 1990, Charter and Gray, 2008; Huang et al., 2001; Kumar and Fullenkamp, 2005; Tichem, 1997; Cowan et al., 2000; Sheu and Chen, 2007).

Once starting to apply DfX, companies have realised how following these principles leads into enormous impacts in company procedures, and even in organisation (Sheu and Chen, 2007). Effective utilisation of DfX methodology requires adequate communication within a company (Skander et al., 2008). In order to achieve the goals set by different DfXs, cooperative work, guidelines, checklists, and software tools are utilised (e.g. Gungor and Gupta, 1999; Bralla, 1996; Huang and Mak, 2003; Boothroyd and Dewhurst, 2008; Eversheim and Baumann, 1991; Poli and Knight, 1984; Scarr, 1986).

In the literature, both theoretical and engineering papers on DfM (and DfX) can be found, however, good descriptions on true practical realisation are scarce as well as optimal organisational solutions for managing these issues.

\section{Research process}

The research process is described in Figure 1. Design for manufacturing, and design for excellence in general, were first studied by using existing literature as the key source. The case company was selected as it is a leading ICT company and, having successfully applied DfM for over a decade, is now expanding DfX to cover ever new aspects. DfM discipline was selected as the focus for this paper as the case company has the lengthiest experience in it, and the related practices are most mature.

Case company was examined in order to obtain an understanding of the company's business. Several workshops were organised together with top managers representing DfM and DfX, as well as related key processes to discuss the practical realisation of DfX in the case company. Interview questions were formulated based on the obtained understanding; see Appendix A.

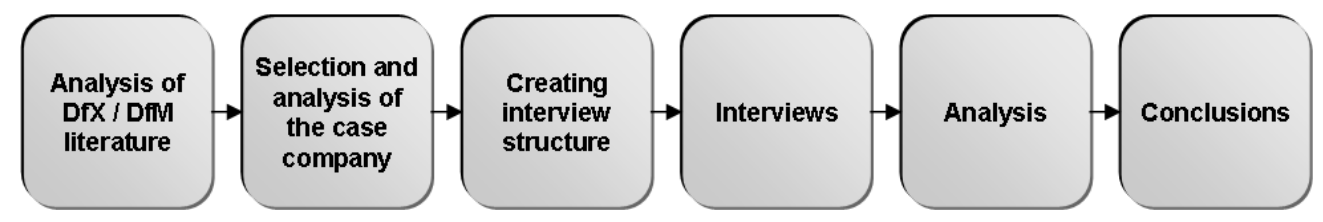

Figure 1. The research process

The study consisted of twenty interviews, comprising multiple sites and countries. The study included all the DfX managers as well as responsible managers for vital internal processes. The case company is currently developing its DfX activities, and is running an internal development project to develop and expand its application of DfX. The researchers were involved in the project and had excellent access to interview all the key experts. The research utilised a semi-structured thematic interview approach (see e.g. Merton et al., 1990). The interviews were conducted informally, in a qualitative manner, allowing the interviewees to explain and clarify the cases and topics as entities. Therefore, these interviews represent the DfX activities in the case company in a versatile manner.

Interviews were transcribed resulting in some twenty to thirty pages for each twenty interviews. As the article focus is on managerial implications, the source material was processed to aid further analysis from this perspective. The findings from each DfM sub-discipline (board assembly, final assembly, testing, and packaging) were condensed into input (where each sub-discipline obtains requirements from and what type they are), output, practical realisation of each sub-discipline and challenges encountered. The results of the analysis are presented in the section 4 Results and analysis. 
The case company has extensive experience over utilising DfM and DfX practices. This, together with the scarceness of similar research, gives the justification to study a descriptive analytical case (see e.g. Siggelkow 2007).

\section{Results and analysis}

\subsection{DfM in the studied company}

The interviewees consider it vital for the business to ensure an adequate capability to deliver products. Customers pay only for functional products that have been delivered according to agreed terms. The studied company continuously streamlines its internal processes for maximum capability to deliver. Delivery capability can, to some extent, be considered separately within production, but it may not be sufficient to obtain adequate results. As a consequence, the studied company utilises the DfX concept to address these challenges already during early NPD.

In the studied company, the role of DfX is to ensure that the needs of manufacturing, supply chain, and after-sales service are taken into account already during product development. Design for manufacturing has been divided into following sub-disciplines: board assembly, final assembly, testing, and packaging. Supply chain aspects cover both the structure and the players of supply chain, and the more operational realisation of the capability to deliver. Other important aspects include, service, environment, and quality. The studied company has a common DfX management organisation, which coordinates different DfX disciplines and sub-disciplines, and communicates their needs into product development. The $D f X$ management is organisationally located under the manufacturing organisation. Each DfX sub-discipline has a named responsible manager. Figure 2 describes the DfX system of the studied company.

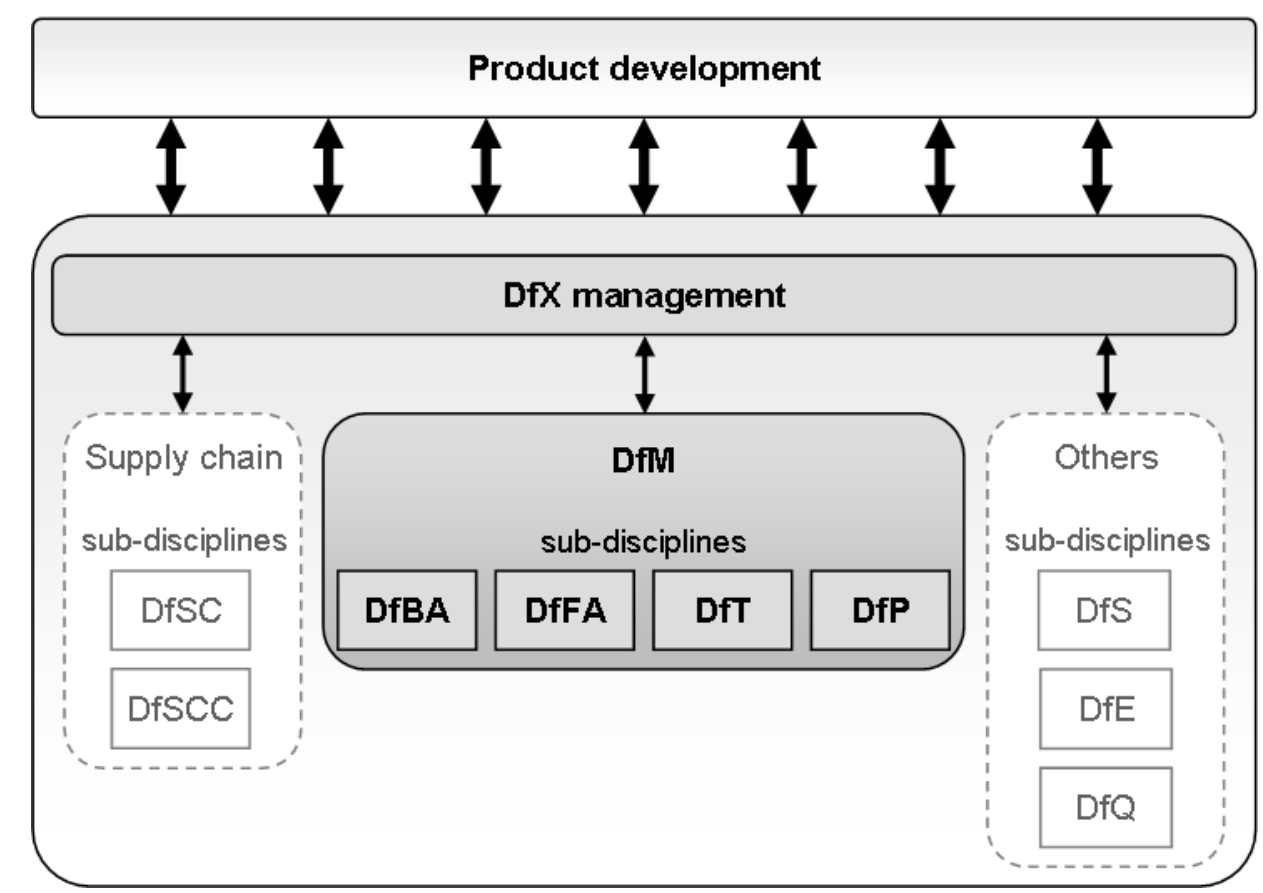

Figure 2 the DfX system of the studied company.

Design for manufacturing (DfM) includes design for board assembly (DfBA), design for final assembly (DfFA), design for testing (DfT), and design for packaging (DfP). The supply chain aspects have been divided into two separate sub-disciplines: design for supply chain (DfSC) covering the structure of the chain, and design for supply chain capability (DfSCC). Other separate sub-disciplines include, design for service (DfS), design for environment (DfE), and design for quality (DfQ).

Each sub-discipline communicates its requirements into product development projects through the DfX management organisation. This communication is supported by organising training sessions for product development personnel. Product development projects have named specialists for each sub- 
discipline, enabling direct feedback. Organisationally, these specialists are a part of product development.

Requirements of each sub-discipline can be categorised by using the following hierarchy:

1. Legislation and business sector standards

2. Company strategy and business targets

3. Customers

4. Internal customers

5. Supply chain

Each DfM sub-discipline is described in more detail below. The descriptions include input (where each DfM obtains requirements from and what type they are), output and practical realisation.

\subsubsection{Design for Board Assembly (DfBA)}

Input: It is seen as the responsibility of DfBA to give NPD feedback, and assure that the manufacturability will be taken into account from the board assembly viewpoint. As inputs to design for board assembly, business management typically defines the intended products and their general requirements. Customer requirements enter DfBA indirectly through product development, or marketing/sales.

Product development projects are seen to define the product, including architecture, PCB (printed circuit board) sizes, materials, board thickness, the type of layers, amount of components, type of components, the use of RF (radio frequency) / digital boards, type of connectors, and such. Also, the way boards are connected to each other, indoor/outdoor use, IP (international protection rating for enclosures) and EMC (electro-magnetic compatibility) requirements are suggested by the product development project.

Production equipment suppliers set requirements for weight, size, component mounting speed, and such. Component suppliers set requirements for component handling, PCB thickness, etc. In addition, requirements include legislation, such as lead-free soldering, and business sector standards.

Output: DfBA is seen to set requirements for product development on manufacturability and is seen to influence product specifications. DfBA provides feedback for product development regarding manufacturing costs on their product proposals. In addition, the manufacturing process may set requirements, for example, the maximum component weight in soldering. DfBA also aims to influence the research phase, in relation to board assembly issues.

Practical realisation: DfBA is seen to aim to prioritise requirements and communicate them. A practical approach is to consider overall costs as the common parameter for prioritisation. It is seen beneficial for product development projects to have clear review points, with a standardised set of requirements.

Understanding the existing production is seen vital in order to learn how to improve future products, and to formulate these learnings into guidelines. Data systems and tools, such as DOORS ${ }^{\circledR}$ and Excel, are utilised to support the practical work of DfBA.

\subsubsection{Design for Final Assembly (DfFA)}

Input: DfFA sets requirements for product development, especially for mechanics designers, providing know-how on how to design for the ease of manufacture. Design for Manufacturing (DfM) is seen to define the key products on which final assembly should focus its efforts. Existing production machinery sets requirements for DfFA that must be taken into account while optimising final assembly related aspects.

Besides manufacturing aspects, DfFA is seen to have an important role in consideration of service aspects. For example, for serviceability, a product must be assembled so that even the bottom PCB can be removed without dismantling the entire product. In addition, requirements include legislation and other general guidelines, such as how much weight an individual employee is allowed to lift.

Output: According to interviewees, cumulative experience has resulted in practices for optimal inclusion of DfFA aspects. The aim is to minimise lead-times, number of parts, tools, successive work 
stages, human errors, and such. Optimising the direction for assembly is also an important aspect. In the beginning of product development, it is not clear how the product will turn out, however, DfFA sets general requirements e.g. to minimise the number of parts. First, technical architecture and technical development related requirements are set. Requirements are more precise towards the end of product development. The requirements described above are communicated to different sites, the target being reaching the employees working hands on in the field.

Practical realisation: It is seen as a good practice to define guidelines for product development, on how to acknowledge the existing production machinery and processes from final assembly viewpoint. Standardised guidelines allow compatibility among multiple products and production sites. Lessons learned from previous projects are seen important for developing DfFA.

DfFA requirements are seen to be attempted to translate into a numerical format to allow designers the ease of prioritisation and effective use of databases.

\subsubsection{Design for testing (DfT)}

Input: Cost-efficient testability in production is seen as the company level target for DfT to address. Existing production technologies, and machinery, guide practical testing. Test technologies are seen to be chosen based on cost calculations, considering quality, cost efficiency, and product structure. Customer requirements typically enter DfT indirectly through product development or marketing/sales. In addition, DfT requirements include legislation, such as product safety issues, and also business sector standards.

Output: DfT is seen to provide guidelines, requirements and targets for product development projects on production testability issues. This includes harmonising processes and defining targets for test designers. Test techniques are typically chosen based on cost calculations for production, considering quality and product structure. Quality in this sense means assuring targeted test coverage, through the utilisation of adequate equipment and process. Test processes are required to be flexible to allow changes in the order different type of tests are conducted.

Simulation tools are seen to be utilised for considering test phases, in order to achieve different quality targets. The results of these simulations are used as a basis for cost calculations.

DfT is seen to provide design requirements and guidelines for product development, based on chosen test techniques. It is seen vital for product development to acknowledge the test techniques production is going to use. These techniques include in-circuit testing, automated optical inspection, $\mathrm{x}$-ray inspection and functional testing. Product architecture significantly affects testability and therefore must be analysed. For example, should there be two alternatives, DfT typically recommends the one more beneficial in terms of production.

Practical realisation: The studied company has multiple production sites, making the practical realisation of DfT challenging. The problem is seen to be accumulated should testing be performed separately for product development, production, and service activities. It is seen vital for DfT to coordinate and optimise testing activities over the entire product development chain, and the entire global network. The target of DfT is to harmonise practices, techniques and equipment between different factories. Some of the interviewees stress the importance of incorporating self-test features into products to allow product development, production and fault finding activities to use the same structures. It is seen important that the cooperation with test specialists and research \& development (R\&D) personnel take place already during the technology development phase. Strategic planning, formulating and communicating road-maps, and common development projects are seen as important for the commitment of relevant stakeholders.

\subsubsection{Design for packaging (DfP)}

Input: Cost efficiency in logistics is seen as a vital target for DfP. Cost analysis includes means for transportation, distribution channels, locations for manufacturing sites and such. DfP is seen to convert these goals into cost and savings targets for each project.

The majority of performance requirements are seen to be received from product development. Typically, customer requirements do not enter DfP directly, but are provided by product development or in some cases by the marketing/sales function. The aim is towards generic solutions, but sometimes 
customers do have unique wishes. Delivered products must be packed in a manner that supports service and maintenance efforts, including repair logistics and routines. In addition to the company logistics organisation, requirements are also received from different players in the supply chain, including the suppliers of packaging materials. DfP requirements also include environmental issues relating to packaging materials.

Output: DfP is seen to set requirements for projects, other parts of the DfX organisation, company suppliers, and a global sourcing organisation. The main goal of DfP is to proactively influence R\&D programmes, especially programme managers, ensuring the packaging aspects of hardware design. DfP has formulated guidelines for ease of packaging, handling, protection of products, and transport efficiency.

DfP sets packaging related requirements also for electronics manufacturing services (EMS) providers. These requirements include norms for testing packages, etc. In addition, DfP sets requirements for procurement of materials, which are to be used in different manufacturing sites.

Practical realisation: Experience on packaging issues is seen to accumulate through time and lessons learned have been documented, providing evidence for communicating and justifying requirements in internal discussions.

Cost calculations are seen as the cornerstone for prioritising and justifying requirements. DfP utilises data systems to describe requirements in numerical terms, allowing the comparison of the lifecycle costs for different alternatives. Design reviews are organised regularly while (product development (PD) projects progress and critical requirements are checked (e.g. critical dimensions and critical hardware (HW) details).

\subsection{Analysis of DfM in the case company}

Design for manufacturing has been conducted for a long period of time in the case company and is seen to function well. In managerial sense, DfX and its sub-disciplines provide principles and general guidelines for product development and at practical level, DfX means exact, often numerical, requirements, tools, design rules and so on. The case company is large, and operates in a multi-site, multi-project, multi-culture environment. It has challenges in prioritising a vast number of different, internal and external, often conflicting requirements. As a solution, the case company strives for using total cost calculations as a basis for this prioritisation. The application of DfX concept has expanded to cover a wider set of activities, including supply chain aspects, reliability, environment and such. However, DfM does still have challenges and must improve continuously.

The case company has established a separate $D f X$ management organisation to coordinate all DfX disciplines and sub-disciplines and to develop and disseminate best practices. The head of $D f X$ management coordinates discipline managers; however, the home functions of these discipline managers have the formal authority. DfX management organisation is not located in product development, opposed to the literature (e.g. Bralla, 1996), but in production that has a role to minimise costs and act as a customer to product development. Additionally, product development projects have named specialists for each sub-discipline, enabling direct feedback. Organisationally, these specialists belong to product development.

\subsubsection{Challenges}

The organisation of the interviewed company is large and complex, resulting in challenges in communication. A single employee can have multiple roles adding to the challenge. Employees tend to understand requirements differently in different parts of product development and other functions. System, mechanical, electronics, and software designers have all their own views. Also, different business units and cultural differences in the global organisation add on to the communication challenge. There are different cultures in different sub-disciplines due to historical reasons, potentially causing conflicts.

Requirements are seen important to be prioritised from the business perspective; however, there is no adequate commensurability to carry out the prioritisation in practice. This means that it is difficult to compare different and sometimes conflicting requirements, as they do not have common economic scale for comparison. The requirements are attempted to prioritise based on end-to-end cost calculations, however, employees are often sceptical about calculations made by other people. As an 
example, following customer wishes of increasing the number of product titles, is in conflict with the desire to minimise the number of these titles. Currently requirements are too often prioritised based on individuals' capability to sell their viewpoint. Product development projects do not always rank the requirements of sub-disciplines as primary issues, especially should the volumes be low. The fact is that people are different and the processes are not always fully standardised.

It seems that DOORS ${ }^{\circledast}$ has been chosen as the common data system to communicate requirements between DfM and product development. However, it is not applied company-wide, other tools exist, and the functioning of DOORS ${ }^{\circledR}$ is not optimal. It is seen to take a lot of experience to formulate requirements into numerical terms in order to product development personnel to understand. Also, for database purposes the requirements must be numerical.

In some cases, the research and development organisation has technology development project before product development projects, they design ASICs (application specific integrated circuit), product architecture, and choose technologies that are important from the DfM viewpoint. Often these choices are close to the final solutions, causing difficulties, should the manufacturing aspect not be addressed early enough.

According to the interviewees, due to the global changes in their conglomerate, some functions, such as testing have had to go back-to-basics, in their approach to emphasise manufacturing and delivery capability aspects, on the expense of the entire product life-cycle. Product lines have been vast in the global organisation, causing additional challenges for requirements management.

Currently bonuses in product development depend on keeping up to schedules, not on how they serve the internal customers in the following phases. This makes it difficult for sub-disciplines to sell the life-cycle aspects.

Table 1 summarises the challenges faced by DfM

Table 1 Key challenges faced by DfM

\begin{tabular}{ll}
\hline & Challenges \\
\hline Data systems & $\begin{array}{l}\text { DOORS }^{\circledR} \text { chosen as company standard } \\
\text { DOORS } \\
\text { formulating requirements into the data-base }\end{array}$ \\
Organisation & $\begin{array}{l}\text { complex organisation } \\
\text { multi-project/ multi-site/ multi-cultural environment } \\
\text { constant changes } \\
\text { multiple roles } \\
\text { communication problematic }\end{array}$ \\
Prioritisation & $\begin{array}{l}\text { contradicting requirements } \\
\text { requirements not commensurable } \\
\text { difficulty of formulating requirements into costs }\end{array}$ \\
Management & $\begin{array}{l}\text { DfX management does not have formal authority over NPD } \\
\text { integration of DfM and technology development } \\
\text { bonus system in NPD }\end{array}$ \\
Product & $\begin{array}{l}\text { complicated product portfolio } \\
\text { complicated products }\end{array}$ \\
\hline
\end{tabular}

\section{Conclusions}

The business environment of the ICT sector is characterised by fierce price erosion. This forces companies to an ongoing process of improving their internal efficiency. In the case company, analysed in this study, design for excellence has proved a functional means for addressing the desire for efficiency improvement and the needs of internal customers. DfX is used to ease communication and to achieve functional integration. DfX is seen as a tangible way to manage requirements throughout 
the entire product development chain, starting from the early stages. This study provides a concrete description on how to organise design for manufacturing in practice.

The case company has extensive experience over DfX, especially on DfM for over a decade. DfM includes the sub-disciplines for board assembly, final assembly, testing, and packaging. The case company has a separate $D f X$ management organisation to coordinate and develop DfX disciplines and sub-disciplines, including DfM and others, and to communicate best practices among the disciplines. The DfX management organisation is located in production that has a role to minimise costs and act as a customer to product development. This is opposed to the literature, which typically places this type of role in product development. The head of $D f X$ management has the role of coordinating the discipline managers, whose home functions, however, have the formal authority. In addition to these arrangements, product development projects have named specialists for each sub-discipline, enabling direct feedback from internal customers. Organisationally, these named specialists belong to product development.

The case company is large, and operates in a complex business environment. It has challenges in prioritising a vast number of different, internal and external, often conflicting requirements. As a solution, the case company strives for using total cost calculations as a basis for this prioritisation. These calculations are the basis for communication between product development and different DfM disciplines.

Currently there are many challenges in the realisation of DfM. The case company operates in a multi-project, multi-site, multi-national, and multi-cultural environment results in communication being demanding. In addition, it is challenging to convert requirements into company data systems in an adequate format. Requirements are not always commensurable, often they are even contradictory, making their prioritisation demanding. Currently, DfM aims to influence early product development which is, however, in some cases too late. There are technology development projects, designing ASICs, and product architectures, before product development which affect manufacturing and should thus be covered by DfX. Tools and databases, such as DOORS ${ }^{\circledR}$ are utilised for managing requirements, however, this is not fully systematic and various challenges, such as the formulation of requirements, exist.

This study describes one of the top companies in its field, which has utilised DfM successfully for over a decade. Concentrating on a single company enabled concrete descriptions on how DfM is organised in practice. According to Yin (2003) analysing a competent organisation increases the validity and reliability of a study. However, a larger number of companies are required prior to generalising the findings. The interviews covered all the key persons involved in DfM and related disciplines, as well as key processes, providing a comprehensive view. Studying a larger amount of companies is a potential topic for future research in order to enable comparison. Another interesting topic for future research would be to study how other companies address the issues identified as challenges in this study.

\section{References}

Barton, J.A. Love, D.M. and Taylor, G.D. (2001) 'Evaluating design implementation strategies using enterprise simulation', International Journal of Production Economics, Vol. 72, No. 3, pp. 285299.

Belt, P., Harkonen, J., Mottonen, M., Kess, P. and Haapasalo, H. (2008) 'Improving the efficiency of verification and validation', International Journal of Services and Standards, Vol. 4, No. 2, pp. $150-166$.

Bengtsson, L. and Berggren, C. (2008) 'The integrator's new advantage - The reassessment of outsourcing and production competence in a global telecom firm', European Management Journal, Vol 26, No. 5, pp. 314-324.

Bralla, J.G. (1996) 'Design for Excellence', 1st edition, McGraw-Hill.

Bras, B. (1997) 'Incorporating Environmental Issues in Product Design and Realization', Industry and Environment, Vol. 20, No. 1-2, pp. 1-19.

Boothroyd, G. and Dewhurst, P. (2008) 'DFMA cost reduction tools - last update', [Available online: http://www.dfma.com 9/30, 2008].

Boothroyd, G. (1983) 'Design for Assembly', Boothroyd Dewhurst. Inc., Wakefield, RI. 
Chang, S.-C., Lin, R.-J., Chang, F.-J. and Chen R.-H. (2007) 'Achieving manufacturing flexibility through entrepreneurial orientation', Industrial Management \& Data Systems, Vol. 107, No. 7, pp. 997-1017.

Chang, S.-C., Lin, R.-J., Chen, J.-H. and Huang, L.-H. (2005) 'Manufacturing flexibility and manufacturing proactiveness: Empirical evidence from the motherboard industry', Industrial Management \& Data Systems, Vol. 105, No. 8, pp. 1115-1132.

Charter, M. and Gray, C. (2008) 'Remanufacturing and product design', International Journal of Product Development, Vol. 6, No. 3-4, pp. 375-392.

Cooper, R.G., Edgett, S.J. and Kleinschmidt, E.J. (2004) 'Benchmarking best NPD practices - III', Research Technology Management, Vol. 47, No. 6, pp. 43-55.

Coulter, S. and Bras, B. (1997) 'Reducing environmental impact through systematic product evolution', International Journal of Environmentally Conscious Design \& Manufacturing, Vol. 6, No. 2, pp.1-10.

Cowan, F.S., Marston, M. and Mistree, F. (2000) 'Design for Excellence: A Microworld, GameTheoretic Approach', Engineering Design Conference 2000: Design for Excellence', Wiley pp. 324.

Dowie, T. (1994) 'Green Design', World Class Design to Manufacture, Vol. 1, No. 4, pp. 32-38.

Ehrenfeld, J. and Lenox, M.J. (1997) 'The development and implementation of DfE programmes', Journal of Sustainable Product Design, Vol. 1, pp. 17-27.

Eversheim, W. and Baumann, M. (1991) 'Assembly-oriented design process', Computers in Industry, Vol. 17, No. 2-3, pp. 287-300.

Gatenby, D.A and Foo, G. (1990) 'Design for X (DFX): Key to competitive, profitable products', AT\&T Technical Journal, Vol. 69, No. 3, pp. 2-13.

Gehin, A., Zwolinski, P. and and Brissaud, D. (2008) 'A tool to implement sustainable end-of-life strategies in the product development phase', Journal of Cleaner Production, Vol. 16, No. 5, pp. 566-576.

Graedel, T.E. (2008) 'A Structured Approach to LCA Improvement Analysis', Journal of Industrial Ecology, Vol. 3, No. 2-3, pp. 85-93.

Gungor, A. and Gupta, S.M. (1999) 'Issues in environmentally conscious manufacturing and product recovery: a survey', Computers \& Industrial Engineering, Vol. 36, No. 4, pp. 811-853.

Gupta, A., Pawara, K.S. and Smart, P. (2007) 'New product development in the pharmaceutical and telecommunication industries: A comparative study', International Journal of Production Economics, Vol. 106, No. 1, pp. 41-60.

Harkonen, J., Belt, P., Mottonen, M., Kess, P. \& Haapasalo, H. (2009) 'Maturity of verification and validation in ICT companies', International Journal of Innovation and Learning, Vol. 6, No. 1, pp. 33-50.

Haque, B. and James-moore, M. (2004) 'Applying Lean Thinking to new product introduction', Journal of Engineering Design, Vol. 15, No. 1, pp. 1-31.

Helo, P. (2004) 'Managing agility and productivity in the electronics industry', Industrial Management \& Data Systems, Vol. 104, No. 7, pp. 567-577.

Huang, G.Q. (1996) 'Implementing Design for X Tools. In: G.Q. Huang, ed, Design for X: Concurrent Engineering Imperatives', 1st edition, Chapman \& Hall, London, pp. 130-152.

Huang, S.H., Kuo, T.C. and Zhang, H.C. (2001) 'Design for manufacture and design for 'X': concepts, applications, and perspectives', Computers \& Industrial Engineering, Vol. 41, No. 3, pp. 241-260.

Jablokow, K.W. and Booth, D.E. (2006) 'The impact and management of cognitive gap in high performance product development organizations', Journal of Engineering and Technology Management, Vol. 23, No. 4, pp. 313-336.

Jiang, J., Shiu, M. and Tu, M. (2007) 'DFX and DFSS: How QFD Integrates Them', Quality Progress, Vol. 40, No. 10, pp. 45.

Jiao, J., Simpson, T.W. and Siddique, Z. (2007) 'Product family design and platform-based product development: a state-of-the-art review', Journal of Intelligent Manufacturing, Vol. 18, No. 1, pp. 5-29.

Jose, A. and Tollenaere, M. (2005) 'Modular and platform methods for product family design: literature analysis', Journal of Intelligent Manufacturing, Vol. 16, No. 3, pp. 371-390. 
Kumar, S. and Fullenkamp, J. (2005) 'Analysis of European Union environmental directives and producer responsibility requirements', International Journal of Services and Standards, Vol. 1, No. 3, pp. 379-398.

Kuo, T.-C., Huang, S.H. and Zhang, H.-C. (2001) 'Design for manufacture and design for ' $\mathrm{X}$ ': concepts, applications, and perspectives', Computers \& Industrial Engineering, Vol. 41, No. 3, pp. 241-260.

Kurk, F. and Eagan, P. (2008) 'The value of adding design-for-the-environment to pollution prevention assistance options', Journal of Cleaner Production, Vol. 16, No. 6, pp. 722-726.

Lai, X. and Gershenson, J.K. (2008) 'Representation of similarity and dependency for assembly modularity', The International Journal of Advanced Manufacturing Technology, Vol. 37, No. 7-8, pp. 803-827.

Lau, A.K.W., Yam, R.C.M. and Tang, E.P.Y. (2007) 'Supply chain product co-development, product modularity and product performance: Empirical evidence from Hong Kong manufacturers', Industrial Management \& Data Systems, Vol. 107, No. 7, pp. 1036-1065.

Maltzman, R., Rembis, K.M., Donisi, M., Farley, M. Sanchez, R.C. and Ho, A.Y. (2005) 'Design for networks - The ultimate design for X', Bell Labs Technical Journal, Vol. 9, No. 4, pp. 5-23.

Merton, R., Fiske, M. and Kendall, P. (1990) 'The Focused Interview: A Manual of Problems and Procedures', 2nd ed. New York: The Free Press.

Pahl, G., Beitz, W., Feldhusen, J., Grote, K.H., Wallace, K. and Blessing, L. (2007) 'Engineering Design - A Systematic Approach', 3rd edition, Springer-Verlag, London.

PoliI, C. and Knight, W.A. (1984) 'Design for forging handbook', Technical Report, Mechanical Engineering Department, University of Massachusetts.

Prasad, B. (1997) 'Re-engineering life-cycle management of products to achieve global success in the changing marketplace', Industrial Management \& Data Systems, Vol. 97, No. 3, pp. 90-98.

Prasad, (2000) 'Converting computer-integrated manufacturing into an intelligent information system by combining CIM with concurrent engineering and knowledge management', Industrial Management \& Data Systems, Vol. 100, No. 7, pp. 301-316.

Rungtusanatham, M. and Forza, C. (2005) 'Coordinating product design, process design, and supply chain design decisions: Part A: Topic motivation, performance implications, and article review process', Journal of Operations Management, Vol. 23, No. 3-4, pp. 257-265.

Scarr, A.J. (1986) 'Product design for automated manufacture and assembly', Annals of the CIRP, Vol. 35, No. 1, pp. 1-5.

Sheu, D.D. and Chen, D.R. (2007) 'Backward design and cross-functional design management', Computers \& Industrial Engineering, Vol. 53, No. 1, pp. 1-16.

Siggelkow, N. (2007) 'Persuasion with case studies', Academy of Management Journal, Vol. 50, No. 1, pp. 20-24.

Skander, A., Roucoules, L. and Meyer, J.S.K. (2008) 'Design and manufacturing interface modelling for manufacturing processes selection and knowledge synthesis in design', The International Journal of Advanced Manufacturing Technology', Vol. 37, No. 5-6, pp. 443-454.

Stoll, H. W. (1988) 'Design for Manufacturing', Manufacturing Engineering, Vol. 100, No. 1, pp. 6773.

Tichem, M. and Storm, T. (1997) 'Designer support for product structuring-development of a DFX tool within the design coordination framework', Computers in Industry, Vol. 33, No. 2-3, pp. 155163.

Tseng, M.M. and Jiao, J. (1998) 'Concurrent design for mass customization', Business Process Management Journal, Vol. 4, No. 1, pp. 10-24.

Yang, C.C., Chen, S.H. and Shiau, J.Y. (2007) 'A DFX and concurrent engineering model for the establishment of a new department in a university', International Journal of Production Economics, Vol. 107, No. 1, pp. 179-189.

Yin, K.Y. (2003) 'Case study research, design and methods', Sage publications. Thousand Oaks, p. 200.

Zeidler, C., Kittl, C. and Petrovic, O. (2007) 'An integrated product development process for mobile software', International Journal of Mobile Communications, Vol. 6, No 3, pp. 345-356. 
Zuidwijk, R. and Krikke, H. (2008) 'Strategic response to EEE returns:: Product eco-design or new recovery processes?', European Journal of Operational Research, Vol. 191, No. 3, pp. 1206-1222.

\section{Appendix A}

Questionnaire

Name

Title

Organisational unit

1. Please describe what you understand with requirements management and requirements? (Specifications, needs, constraints, etc.)

- How do requirements relate to your area of responsibility

2. Where does your organisation unit get its requirements?

- What type of requirements - please give examples

3. To which organisational units, within the company, do you set requirements?

- What type of requirements - please give examples

4. How are requirements prioritised?

- How would you develop the prioritisation of requirements

5. What are the main challenges relating to requirements management form your organisational unit's perspective - How would you attempt to rectify these issues?

6. How do you view DfX (Design for Excellence)?

7. How does the view over requirements vary - in your opinion - in different parts of the company (for example different sites, different functions: product development, production etc.)?

8. How have the changes in the company organisation influenced requirements management? 